\title{
Tuberculosis care for pregnant women: a systematic review
}

\author{
Hang Thanh Nguyen ${ }^{1 *}$, Chiara Pandolfini ${ }^{1}$, Peter Chiodini ${ }^{2}$ and Maurizio Bonati ${ }^{1}$
}

\begin{abstract}
Background: Tuberculosis (TB) during pregnancy may lead to severe consequences affecting both mother and child. Prenatal care could be a very good opportunity for TB care, especially for women who have limited access to health services. The aim of this review was to gather and evaluate studies on TB care for pregnant women.

Methods: We used a combination of the terms "tuberculosis" and "pregnancy", limited to human, to search for published articles. Studies reflecting original data and focusing on TB care for pregnant women were included. All references retrieved were collected using the Reference Manager software (Version 11).

Results: Thirty five studies were selected for review and their data showed that diagnosis was often delayed because TB symptoms during pregnancy were not typical. TB prophylaxis and anti-TB therapy appeared to be safe and effective for pregnant women and their babies when suitable follow up and early initiation were present, but the compliance rate to TB prophylaxis is still low due to lack of follow up and referral services. TB care practices in the reviewed studies were in line in principle with the WHO International Standards for Tuberculosis Care (ISTC).

Conclusions: Integration of TB care within prenatal care would improve TB diagnosis and treatment for pregnant women. To improve the quality of TB care, it is necessary to develop national level guidelines based on the ISTC with detailed guidelines for pregnant women.
\end{abstract}

Keywords: Delivery of health care, Pregnancy, Tuberculosis, Women

\section{Background}

According to the World Health Organization (WHO), every year about 700,000 women die of tuberculosis (TB) and over three million contract the disease [1]. TB is the third leading cause of death among women aged 15-44. TB can cause infertility and contributes to poor reproductive health outcomes $[2,3]$.

When pregnant women contract $\mathrm{TB}$, the disease is more difficult to diagnose because TB symptoms such as fatigue, shortness of breath, sweating, tiredness, cough, and mild fever are similar to physiological symptoms of pregnancy. Untreated TB or TB treated late may lead to severe consequences affecting both mother and child $[4,5]$. Pregnant women with pulmonary TB who are treated appropriately do not have increased rates of maternal or neonatal complications, while without treatment, TB can lead to

\footnotetext{
* Correspondence: hang.nguyen@marionegri.it

'Department of Public Health, Laboratory of Maternal and Child Health, IRCCS - Istituto di Ricerche Farmacologiche Mario Negri, Via G. La Masa 19, Milan, Italy

Full list of author information is available at the end of the article
}

increased neonatal morbidity, low birth weight, prematurity, and increased pregnancy complications, including four-fold increases in maternal morbidity due to higher rates of abortion, post partum haemorrhage, labour difficulties, and pre-eclampsia [5]. Prenatal care could be a very good opportunity for $\mathrm{TB}$ screening and diagnosis and for following up TB care, especially for women who have limited access to health services, such as migrants or women of limited social/economic status, who only approach medical services when pregnant $[4,5]$.

The WHO Guidelines for Treatment of Tuberculosis provide recommendations for $\mathrm{TB}$ care and recommend the integration of $\mathrm{TB}$ care within both prenatal care procedures and the Preventing Mother to Child Transmission of HIV Program (PMTCT) in order to utilise existing health resources and systems to improve accessibility and effectiveness of TB care for pregnant women and prevent the mother to child transmission of TB [6].

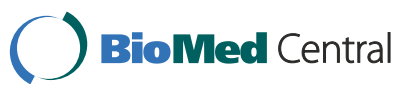

(c) 2014 Nguyen et al.; licensee BioMed Central Ltd. This is an Open Access article distributed under the terms of the Creative Commons Attribution License (http://creativecommons.org/licenses/by/4.0), which permits unrestricted use, distribution, and reproduction in any medium, provided the original work is properly credited. The Creative Commons Public Domain Dedication waiver (http://creativecommons.org/publicdomain/zero/1.0/) applies to the data made available in this article, unless otherwise stated. 
Regardless of the importance of TB care in the prenatal period, however, only a modest number of articles addressing $\mathrm{TB}$ in pregnant women have been published. Some major controversial issues in TB care during pregnancy remain that require further research, such as the safety, reliability, and feasibility of TB screening methods used in the prenatal period [7], drug therapy for pregnant MDR women [8], and delay of treatment until the post partum period in case of latent tuberculosis infection (LTBI) [9]. LTBI is a condition in which a person is infected with Mycobacterium tuberculosis, but does not currently have active tuberculosis disease.

This systematic review aimed to gather and evaluate evidence based studies on TB care in pregnancy, with consideration of WHO standard guidelines for TB care, in order to recommend better practices to improve TB care for pregnant women. For studies on TB care in pregnancy the authors intended those addressing screening/diagnosis, prevention, treatment, or followup/supervision/counselling activities/services for women in pregnancy.

\section{Methods}

The following databases were searched for articles in English, published in any year up to December 31, 2012: MEDLINE (indexes articles dating back to 1946), EMBASE (1973), the Cochrane Library (various), and www.clinicaltrials.gov (2000). The search strategies involved 1. using the $\mathrm{MeSH}$ terms "tuberculosis" and "pregnancy", limited to human; 2. the terms "tuberc" and "pregnan" as free text within articles indexed in the last 90 days, limited to human; 3. combining the results of MeSH "tuberculosis" and free text "tuberc"; ; 4. combining the results of MeSH "pregnancy" and free text "pregnan";"; 5. combining the results of steps 3 and 4 (pregnancy AND tuberculosis, limited to Human). The syntax was adjusted for the specific databases. Reference lists were then searched for potentially relevant articles.

\section{Inclusion criteria}

Studies reflecting original data and focusing on TB care (screening, diagnosis, treatment, and follow up) in pregnant women.

\section{Exclusion criteria}

Articles were excluded if: 1 . The target group was NOT pregnant women, 2. TB was mentioned, but NOT TB care (i.e. TB as a complication of other diseases, as part of a study on infectious diseases, etc.); 3 . Original data was not included 4. They were NOT studies (letters, presentations, conference documents, case reports).

Figure 1 summarizes the selection process for review articles with detailed number of articles in each step.

\section{Data extraction and assessment}

All references retrieved were collected and analysed using the Reference Manager (Version 11) program. All identified abstracts were read for their applicability to inclusion and

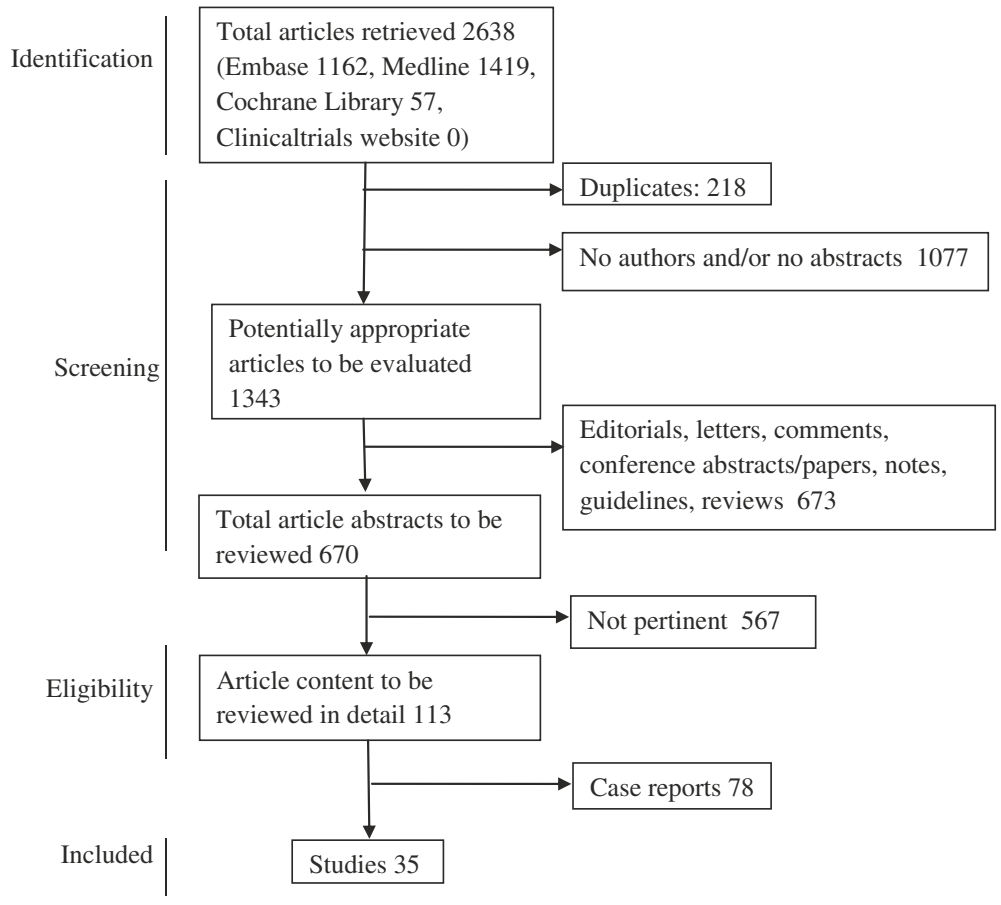

Figure 1 PRISMA Flow diagram of search strategy. 
exclusion criteria by two co-reviewers and discrepancies were resolved by a third reviewer. Potentially relevant articles were obtained and examined, and the quality of selected studies was assessed by two evaluators using the checklists from the National Institute for Health and Clinical Excellence (NICE)'s manual for developing public health guidance [10] (See Additional file 1). Each study was evaluated by the appropriate NICE checklist depends on study type. The quality evaluation took into consideration the studies' internal and external validity. According to NICE guidelines, a study was rated good quality $(++)$ if it fulfilled all or most of criteria in the check list, medium quality if it fulfilled some $(+)$, and low quality if few or no criteria were fulfilled (-) [10]. Inter-reviewer reliability was measured using Cohen's Kappa statistics. Discrepancies were addressed by a third reviewer. MS Excel software was used to process data from the selected studies.

\section{Details of ethics approval}

This is a systematic review of previously published data and therefore does not require ethical approval.

\section{Results}

\section{Summary of included studies}

Thirty five studies were selected for detailed review. Good inter-rater agreement on the quality assessment of the studies was found $(K=0.70)$. There were 6 studies with good quality $(++), 21$ with medium quality $(+)$, and 8 with low quality (-). The reasons to include studies with low quality is the limited number of studies in selected topics and one of the purpose of this review is to have an overall evaluation on the situation of research on TB care for pregnant women.

Table 1 shows the characteristics of the reviewed studies and the quality evaluation scores. Concerning the study types, there were 14 cohort studies, 8 before and after studies, 6 cross sectional studies, 4 case control studies, 2 controlled trials, and 1 qualitative study.

Concerning the topics addressed, some studies addressed multiple topics: 8 studies covered 2 topics and 1 study covered 3. The topic of TB diagnosis/screening was presented in 21 studies, 14 studies addressed TB treatment (including 4 on MDR treatment), 2 studies were on TB prevention, specifically on LTBI prophylaxis, and 3 studies were on the follow-up of women's compliance to the TB prophylaxis therapy. All studies were published after 1975, with a majority (26/35) published after 1999 . Data originated from 16 different countries. Fifteen studies were carried out in resource-rich countries: US (11 studies), UK (3), and the Netherlands (1), while 20 were carried out in resourcelimited countries: South Africa (6 studies), India (3), and the remaining countries had 1 each. One group of researchers in South Africa conducted 3 studies [22,32,44], other studies were all conducted by different groups of researchers. In all, 81093 people were enrolled in these studies, 37404 of whom in the study group (pregnant women with TB) and 43689 in the controlled/comparison groups (pregnant women without TB or/and non-pregnant women with TB). The large total was mostly due to one population based study involving 61016 people [14].

\section{TB diagnosis and screening for pregnant women}

The procedures for TB screening and diagnosis for pregnant women described in the reviewed studies include the tuberculin sensitivity test (TST/PPD) followed by the sputum test (Acid-fast bacillus - AFB) and the shielded chest X-ray $[18,19,23,24,30]$. The AFB smear test appears to have low sensitivity in pregnant women $[18,19,30]$, but is still used in low resource settings as part of the procedure for diagnosing active TB due to its low cost and simple technique $[13,30]$. AFB culture was used as a confirmation of diagnosis, but is time consuming and not available in low resource settings [13,23]. Another technique, fluorescence microscopy, was recommended as a substitute for AFB culture because it is cheaper [13]. This procedure is for pulmonary TB cases and cannot identify extra pulmonary TB without additional tests and presence of physical TB symptoms. A clinical examination comprising a questionnaire tracking TB history and detecting TB clinical symptoms was also used and was proven to increase reliability of TB screening and diagnosis when combined with paraclinical tests $[13,23,27,30,41]$. Some authors recommended not using chest X-ray for pregnant women if there were no clinical symptoms of TB [30].

TST is used widely as the first step in TB screening and diagnosis and to identify LTBI [18]. Studies showed that pregnancy does not affect the sensitivity of this test [20], but its result can be affected by HIV infection or any situation that severely weakens the immune system (such as disseminated TB), as these could lead to false negative results $[21,30,45]$. BCG vaccination can also lead to TST positive results in healthy women $[11,28]$. In a high HIV prevalence setting, other tests and clinical symptoms should therefore be taken into account in diagnosing TB [41] and the TST and anergy skin tests (the latter is used to evaluate whether the immune system is functioning properly or not and can indicate whether the results of the other skin test are reliable) are recommended as a TB screening method in the prenatal care procedures [31]. In populations in which the majority of people are BCG vaccinated or their vaccination status is uncertain, TST is discouraged and IGRA is recommended for TB screening and diagnosis [11,28].

Concerning the IGRA test, one study in Kenya compared results of this test with the TST in screening for TB and showed the advantage of the IGRA test over TST in TB screening and diagnosis for HIV positive pregnant women, since its sensitivity is not affected by 
Table 1 Characteristics of reviewed studies and quality evaluation results, sorted by quality evaluation score

\begin{tabular}{|c|c|c|c|c|c|c|c|c|}
\hline No. & $\begin{array}{l}\text { Authors/Year published } \\
\text { (reference) }\end{array}$ & $\begin{array}{l}\text { Year data } \\
\text { collected }\end{array}$ & Study type & Topic & No. of cases & Length of study & Country & $\begin{array}{l}\text { Quality score* } \\
\text { (from high to low) }\end{array}$ \\
\hline 1 & Worjoloh et al./2011 [11] & $\begin{array}{l}5 / 2009- \\
3 / 2010\end{array}$ & Cross sectional & Screening & 220 & 10 months & US & ++ \\
\hline 2 & Sangala et al./2006 [12] & 2006 & Qualitative & Screening & $\begin{array}{l}40 \text { (15 pregnant, } 15 \text { non pregnant, } 10 \\
\text { antenatal care providers) }\end{array}$ & N/A & Malawi & ++ \\
\hline 3 & Gounder et al./2011 [13] & $\begin{array}{l}12 / 2008- \\
7 / 2009\end{array}$ & Cross sectional & $\begin{array}{l}\text { Screening, } \\
\text { prevention }\end{array}$ & 3963 & 7 months & $\begin{array}{l}\text { South } \\
\text { Africa }\end{array}$ & ++ \\
\hline 4 & Czeizel et al./2001 [14] & 1980-1996 & Case control & Treatment & 61016 (38151 controls and 22865 cases) & 16 years & Hungary & ++ \\
\hline 5 & Tripathy et al./2003 [15] & $1986-2001$ & Prospective cohort study & Treatment & $\begin{array}{l}213 \text { (111 pregnant with TB, } 51 \text { pregnant } \\
\text { without TB, } 51 \text { non pregnant with TB) }\end{array}$ & 15 years & India & ++ \\
\hline 6 & Jana et al./1999 [16] & 1983-1993 & Case control & Treatment & $\begin{array}{l}165 \text { (33 pregnant with TB, } 132 \text { pregnant } \\
\text { without TB) }\end{array}$ & 10 years & India & ++ \\
\hline 7 & $\begin{array}{l}\text { Figueroa-Damian et al./ } \\
1998[17]\end{array}$ & 1990-1995 & Case control & Treatment & $\begin{array}{l}100 \text { ( } 25 \text { pregnant with TB, } 75 \text { pregnant } \\
\text { without TB) }\end{array}$ & 5 years & Mexico & + \\
\hline 8 & Carter et al. /1994 [18] & 1987-1991 & Retrospective cohort study & Diagnosis & 22 (7 pregnant, 15 nonpregnant) & 4 years & US & + \\
\hline 9 & Doveren et al./1998 [19] & 1990-1996 & Retrospective cohort study & Diagnosis & 14 (5 pregnant, 9 non pregnant) & 6 years & Netherlands & + \\
\hline 10 & Present et al./1975 [20] & 1975 & Non-randomized controlled trial & Diagnosis & 326 (167 pregnant, 226 non- pregnant) & 1 year & US & + \\
\hline 11 & $\begin{array}{l}\text { Jonnalagadda et al./2010 } \\
\text { [21] }\end{array}$ & $\begin{array}{l}1997- \\
2005\end{array}$ & Prospective cohort study & Diagnosis & 333 & 8 years & Kenya & + \\
\hline 12 & Khan et al./2001 [22] & 1996-1998 & $\begin{array}{l}\text { Prospective study cohort 1997- } \\
1998, \text { retrospective cohort study } \\
1996\end{array}$ & Diagnosis & 101 & 3 years & $\begin{array}{l}\text { South } \\
\text { Africa }\end{array}$ & + \\
\hline 13 & Knight et al./2009 [23] & 2005-2006 & Cross sectional & Diagnosis & 33 & 1 year & UK & + \\
\hline 14 & Kothari et al./2006 [24] & $\begin{array}{l}1 / 1997- \\
12 / 2001\end{array}$ & Before and after study & $\begin{array}{l}\text { Diagnosis, } \\
\text { treatment, } \\
\text { follow-up }\end{array}$ & 32 & 5 year & UK & + \\
\hline 15 & Kwara et al./2008 [25] & 2003 & Retrospective cohort study & Follow up & 845 (97 pregnant women) & 1 year & US & + \\
\hline 16 & Cruz et al./2005 [26] & 2000 & Retrospective cohort study & Follow-up & 425 & 1 year & US & + \\
\hline 17 & Kali et al./2006 [27] & $\begin{array}{l}6 / 2003- \\
10 / 2003\end{array}$ & Cross sectional & Screening & 370 & 4 months & $\begin{array}{l}\text { South } \\
\text { Africa }\end{array}$ & + \\
\hline 18 & $\begin{array}{l}\text { Sepulveda et al./1995 } \\
\text { [28] }\end{array}$ & 1991-1994 & Prospective cohort study & Screening & 840 & 3 years & Chile & + \\
\hline 19 & Meints et al./2010 [29] & 2003-2006 & Cross sectional & Screening & 1767 & 4 years & US & + \\
\hline 20 & Sheriff et al./2010 [30] & $\begin{array}{l}6 / 2008-8 / \\
2008)\end{array}$ & Cross sectional & Screening & 286 & 2 months & Tanzania & + \\
\hline 21 & Mofenson et al./1995 [31] & $\begin{array}{l}9 / 1989-3 / \\
1993\end{array}$ & Prospective cohort study & $\begin{array}{l}\text { Screening, } \\
\text { diagnosis }\end{array}$ & $\begin{array}{l}183 \text { ( } 65 \text { pregnant and } 118 \text { non- } \\
\text { pregnant) }\end{array}$ & 3.5 years & $\begin{array}{l}\text { US and } \\
\text { Puerto Rico }\end{array}$ & + \\
\hline 22 & Pillay et al./2001 [32] & 1996-1998 & Prospective cohort study & $\begin{array}{l}\text { Screening, } \\
\text { diagnosis }\end{array}$ & 146 & 2 years & $\begin{array}{l}\text { South } \\
\text { Africa }\end{array}$ & + \\
\hline
\end{tabular}


Table 1 Characteristics of reviewed studies and quality evaluation results, sorted by quality evaluation score (Continued)

\begin{tabular}{|c|c|c|c|c|c|c|c|c|}
\hline 23 & Margono et al./1994 [33] & 1985-1992 & Before and after study & $\begin{array}{l}\text { Screening, } \\
\text { diagnosis, } \\
\text { treatment }\end{array}$ & 16 & 7 years & US & + \\
\hline 24 & $\begin{array}{l}\text { Lighter-Fisher et al./2012 } \\
\text { [34] }\end{array}$ & 2012 & Non-randomized controlled trial & $\begin{array}{l}\text { Screening, } \\
\text { diagnosis }\end{array}$ & $\begin{array}{l}280 \text { ( } 140 \text { pregnant women, } 140 \text { non } \\
\text { pregnant women) }\end{array}$ & N/A & US & + \\
\hline 25 & Donald et al./1991 [35] & 1991 & Retrospective cohort study & Treatment & $\begin{array}{l}30 \text { children with mothers who received } \\
\text { streptomycin injection during pregnancy }\end{array}$ & N/A & $\begin{array}{l}\text { South } \\
\text { Africa }\end{array}$ & + \\
\hline 26 & Palacios et al./2009 [36] & $\begin{array}{l}1996 \\
-2005\end{array}$ & Before and after study & $\begin{array}{l}\text { Treatment } \\
\text { (drug resistant) }\end{array}$ & 38 & 10 years & Peru & + \\
\hline 27 & Tabarsi et al./2011 [37] & 2003-2009 & Before and after study & $\begin{array}{l}\text { Treatment } \\
\text { (drug resistant) }\end{array}$ & 5 & 6 years & Iran & + \\
\hline 28 & Cheng et al./2003 [38] & 2002 & Before and after study & $\begin{array}{l}\text { Diagnosis, } \\
\text { treatment }\end{array}$ & 29 & $\begin{array}{l}\text { Done in } 2002 \text { with } \\
\text { article search 1966- } \\
2002\end{array}$ & $\begin{array}{l}\text { Hong Kong, } \\
\text { China }\end{array}$ & - \\
\hline 29 & Franks et al./1989 [39] & 1980-1982 & Case control & Prevention & $\begin{array}{l}7629 \text { (3681 pregnant, } 3948 \text { non- } \\
\text { pregnant) }\end{array}$ & 18 months & US & - \\
\hline 30 & Sackoff et al./2006 [40] & $1999-2000$ & Retrospective cohort study & $\begin{array}{l}\text { Prevention, } \\
\text { follow-up }\end{array}$ & 730 & 1 year & US & - \\
\hline 31 & Gupta et al./2011 [41] & $2002-2007$ & Retrospective cohort study & Screening & 799 & 5 years & India & - \\
\hline 32 & Keskin et al./2008 [42] & $2000-2005$ & Before and after study & Treatment & 5 & 5 years & Turkey & - \\
\hline 33 & $\begin{array}{l}\text { De Oliveira et al./2011 } \\
\text { [43] }\end{array}$ & $1995-2007$ & Before and after study & $\begin{array}{l}\text { Treatment } \\
\text { (drug resistant) }\end{array}$ & 7 & 13 years & Brazil & - \\
\hline 34 & Khan et al./2007 [44] & $1996-2001$ & Before and after study & $\begin{array}{l}\text { Treatment } \\
\text { (drug resistant) }\end{array}$ & 5 & 5 years & $\begin{array}{l}\text { South } \\
\text { Africa }\end{array}$ & - \\
\hline 35 & Llewelyn et al./2000 [45] & $\begin{array}{l}12 / 1995- \\
5 / 1998\end{array}$ & Prospective cohort study & $\begin{array}{l}\text { Diagnosis, } \\
\text { treatment }\end{array}$ & 13 & 30 months & UK & - \\
\hline
\end{tabular}

(++): High quality; (+) Medium quality; (-) Low quality. 
HIV infection [21]. Two studies proved the value of IGRA in detecting LTBI in pregnant women, since the results of this test were not affected by BCG vaccination, thus avoiding the TST false positive result and the unnecessary, consequent INH prophylaxis [11,21].

\section{Prevention}

TB prevention includes BCG vaccination in childhood and INH prophylaxis for LTBI positive people. There were 2 studies on TB prevention and both were on INH prophylaxis for LTBI pregnant women. Both were conducted in the US with pregnant women of foreign origin and LTBI was diagnosed by TST $[39,40]$. One study [40] showed a low completion rate of INH therapy ( $9.3 \%$ ) and the other showed a high risk of INH toxic hepatitis, with pregnant women having a 2.5 fold greater risk of INH hepatitis than non-pregnant women (but this result was not statistically significant due to the small number of women) [39]. The 2 studies found that the main reason for this discouraging result was a lack of follow up and referral services for pregnant women undergoing INH prophylaxis $[39,40]$.

\section{Treatment}

There were 375 pregnant women with TB in the 14 studies on TB treatment. Treatment outcome was generally positive, with 332/375 women cured (confirmed by AFB culture conversion). In terms of mortality, 25 women died during treatment, 11 of whom died due to meningitis TB, 11 due to MDR-TB, 2 due to acute respiratory distress syndrome (ARDS), and 1 due to a nonTB related reason (massive pulmonary embolism). Other than mortality, the negative treatment outcomes included 4 treatment failures, 4 cases of residual functional deficit, 7 treatment terminations due to adverse drug effects, and 3 cases of treatment abandonment.

In terms of pregnancy outcome, only 11 women chose to terminate the pregnancy when they discovered their TB situation, while the others continued the pregnancy and underwent TB therapy. Among the pregnant women undergoing TB therapy, 332 women gave birth, 1 had a therapeutic abortion, 3 had miscarriages, 3 had stillborns, and 25 died. Concerning the 332 cases of mothers who gave birth, 4 infants died shortly after birth due to pneumonia and prematurity, 2 were HIV positive, 1 had active TB, 2 had LTBI, 50 were low birth weight, and 7 had growth restriction. Studies also showed that HIV infected women were more likely to choose pregnancy termination and had higher mortality and morbidity rates, even with intensive TB treatment combined with HIV treatment $[33,44]$.

The first line drugs used for pregnant women in the studies included INH, ethambutol (ETB), rifampicin (RIF), and, in some cases of extra pulmonary $\mathrm{TB}$, pyrazinamid
(PZA) $[15,19,33,45]$. In the MDR cases, the second line drugs, including drugs of the amino glycosides group, fluoroquinolone, thioamides, cycloserines, and terizidone, were used in combination with effective first line drugs, and the treatment regime depended on the drug resistance situation of the individual cases $[36,37,43,44]$.

Regarding effectiveness and safety of anti-TB drugs, results of the reviewed studies showed no significant association between child abnormality and mother's exposure to anti-TB drugs, both for $1^{\text {st }}$ and $2^{\text {nd }}$ line antiTB drugs during pregnancy $[14,15,37,43,44]$. Other significant adverse effects were recorded in a very small number of pregnant women (2 cases of drug induced hepatitis, 2 of PZA allergy, 2 of sensorineural deafness, and 1 of severe nausea and jaundice) and led to termination of therapy without mortality $[24,44]$. Streptomycin (SM) was not used in any studies because of its potential risk of deafness in babies. However, a retrospective study was conducted, checking the hearing capacity of 30 children whose mothers received SM injection during pregnancy, and found no significant effect, with only one case of deafness possibly linked to the mother's use of SM. Authors of this study recommend only using SM after the $2^{\text {nd }}$ trimester if really necessary [35].

There were 4 studies with 55 pregnant women on MDR treatment. Unlike other studies, in these TB was detected in all the women before pregnancy. More specifically, 48/ 55 of the women had been diagnosed with MDR TB and had already taken $2^{\text {nd }}$ line anti-TB drugs before getting pregnant, while 7/55 were diagnosed MDR TB and started therapy during pregnancy $[36,37,43,44]$. After being counselled by clinicians, only 6/55 women chose abortion, while the rest decided to continue the pregnancy and undergo MDR therapy $[37,44]$. Eleven women died (8 died during treatment and 3 died after completing treatment for unknown reasons). There was one stillbirth and one child died prematurely due to pneumonia. One woman and her child were lost to follow up. One woman had to terminate treatment due to hepatitis. Other cases were treated successfully. The results of the studies showed that, with an attentive follow-up and appropriate therapy, MDR-TB pregnant women can be cured and have a positive maternal outcome, and should therefore be given the option to continue with a pregnancy $[36,37,44]$. The results also showed that a delay in, or default, MDR treatment were the main causes of mortality and morbidity for mothers and babies $[36,43,44]$.

\section{Follow-up}

Follow-up actions for TB therapy include checking for a woman's drug consumption, clinical symptoms of antiTB drug adverse effects, and liver function tests. Good compliance with TB treatment in pregnant women led to better maternal outcome and TB recovery rate. These 
studies showed that adequate health services and directly observed therapy (DOT) could greatly contribute to women's compliance, and, therefore, to treatment success $[36,45]$.

There were 3 studies on follow-up of TB therapy for pregnant women and all were on INH prophylaxis. Pregnant women with LTBI were offered 6 months of prophylaxis with INH. The compliance rate was low, possibly due to the women's concern about hepatitis and other adverse effects $[25,40]$, and the lack of referral services for treatment evaluation and action from health care providers to ensure compliance [40]. Compared to the general population, pregnant women were less likely to initiate the INH prophylaxis $-52.1 \%$ vs $14.7 \%$ [25]. In all 3 studies, the completion rate among pregnant women was very low $(14.7 \%$, $9.3 \%$, and $21.2 \%)[25,26,40]$. All studies recommended that health care providers implement better follow-up strategies to increase patient compliance in the prenatal and postpartum periods, ensure follow-up of drug adverse effects, and not dispense INH quantities covering more than 30 days of treatment at each visit.

\section{Discussion}

\section{Main findings}

In resource-rich countries, pregnant women with high $\mathrm{TB}$ prevalence are migrants and people of foreign origin $[11,18,23,24,28,45]$, while in resource-limited countries, HIV infected pregnant women are the group with high TB prevalence and mortality $[13,22,27,32,41]$.

The major problem concerning TB diagnosis for pregnant women is the delay in diagnosis, with a median delay time, defined as the duration from symptom onset to confirmation of diagnosis, ranging from 7 days to 6 months. The main reasons for this delay are that women seek health services and prenatal care at a late stage of their pregnancy and that TB during pregnancy is asymptomatic or has nonspecific symptoms, especially in cases of extra pulmonary TB $[18,23,38,45]$. Compared to non-pregnant women, pregnant women were more likely to be diagnosed with TB via routine screening (as part of prenatal care) [30]. In HIV infected people, the difficulty in diagnosis is even greater since the weak immune reaction may cause false negative TST and make early TB symptoms unclear [21,32]. Thus, all studies recommended the integration of TB screening in prenatal care procedures for high risk groups.

In terms of treatment, studies have shown the importance of starting treatment as soon as possible, even before $\mathrm{TB}$ culture results, to revert the negative impact of $\mathrm{TB}$ on mothers and babies [17,24,33,45]. Early treatment of TB $\left(1^{\text {st }}\right.$ and $2^{\text {nd }}$ trimester) led to a maternal outcome comparable to that of non-TB infected pregnant women, and to a much better outcome than that of women who received late treatment [17]. Authors also recommended making
TB culture mandatory since it is the most reliable standard for confirming TB infection and treatment effectiveness, and for revising the therapy in case of lack of success $[15,33]$. Treatment of extra PTB had a less positive prognosis than PTB due to greater difficulty in diagnosis and treatment [16,38]. If women are diagnosed and treated with anti-TB early, however, the maternal outcome can be positive [16,24,33,45].

The low LTBI treatment completion rates raised concerns about LTBI prophylaxis during pregnancy. Follow up actions for LTBI in reviewed studies required women go to the health clinics for check-ups and to obtain more medication, but no onsite enforcement in the community/family, such as DOT or visits, was provided to reinforce patient compliance $[25,26,40]$. These studies showed the importance of health services in follow-up, since pregnant women who receive health care from the same clinician before and after delivery, who have insurance, or who receive continuous care from clinics outside hospitals were more likely to complete the therapy $[25,26]$.

\section{Strengths and limitations}

The strength of the review is that all aspects of TB care in different settings were considered and reviewed and that the authors could therefore use the WHO ISTC as a standard to which to compare TB care practices. However, the review has some limitations. The studies reviewed were of limited quality and covered multiple aspects of TB care, no intensive analysis for each aspect could therefore be performed. There was a limited number of populationbased studies, since most were conducted in a single clinic. Results are therefore not solid enough to be applicable to a larger population. Another limitation was that few studies had control groups; some used comparison groups that were not fully comparable with the study group [16-18,20,25,28,31,39]. Furthermore, the study designs were weak, since no randomised controlled trials were present. Only one qualitative study was found, and with a disease related to socio-economic status and poverty as is TB, additional qualitative studies would have been useful in identifying attitudes, behaviours, challenges, and opportunities for shaping effective interventions/ policies for better care for TB patients. A more general limitation is that the differing resources available between different countries make it difficult to generalise the conclusions.

\section{Interpretation}

According to the WHO guidelines, the ISTC applies to the general population, with only a notion on avoiding using streptomycin in treatment during pregnancy $[6,46]$. In principle, TB care practices in the reviewed studies were consistent with the ISTC. However, in resource-limited 
countries some standards could not be put into practice (See Additional file 2).

Since the WHO guidelines focus on resource-limited countries with high TB prevalence, these may not be entirely appropriate for resource-rich countries. The comparison with the ISTC also revealed that, although TB diagnosis and treatment facilities in resource-rich countries are better, the role of counselling and support/supervision has not drawn enough attention on the part of health care providers and researchers in such countries, albeit WHO considers these as important standards to ensure patient compliance to TB treatment.

\section{Conclusions}

Review results have proven both the importance of TB care in reducing TB mortality and morbidity for women and their babies, and the feasibility of TB control interventions, even in limited resource settings. Several recommendations to improve the quality of TB care for pregnant women can be made based on the results of the review:

TB care for pregnant women should utilise available health system resources, especially the antenatal care programs, and should include the patient-centred approach in counselling, supervision, and support as well as a wellmanaged, nation-wide method of treatment record keeping to ensure patients' compliance to TB treatment.

Concerning the target of TB care, in resource-rich countries screening interventions should focus on the foreign origin population, while in resource-limited countries interventions should focus on areas with low socio-economic status and high prevalence of HIV infection.

Raising doctors' awareness on TB is fundamental. When visiting women with unclear symptoms such as fever, doctors should consider TB and investigate the woman's history and prescribe TB tests in order not to delay diagnosis and to avoid severe consequences.

Concerning TB diagnostic tests, considering the low sensitivity of the AFB smear test in diagnosis for pregnant women and the advantage of the IGRA test over the AFB smear test, IGRA is recommended in diagnosis and screening if possible. Further studies are therefore needed on its specificity and reliability, and on its applicability to a wider population.

Additional studies on TB therapies for pregnant women should be performed, given their scarcity, especially for MDR TB.

Before deciding to start the TB preventive therapy, BCG vaccination status should be confirmed, and during therapy, the test to detect INH adverse effects should be conducted regularly. More active involvement of health care providers in following up women's compliance could improve the low completion rate of therapy.

Information on individual/family history of TB infection, BCG vaccination, and past treatment, for example, were hardly collected. Collecting such information from patients during the first visit and giving this step high priority could help to improve diagnosis and treatment.

Additional studies, both qualitative and quantitative, and clinical and community-based, need to be performed and should not only address the quality of TB care provided by service providers, but also the behaviours and attitudes of individuals and communities in approaching and using available health services and the barriers faced in accessing and complying with $\mathrm{TB}$ treatment. It would be especially important to address issues such as carrying out TB cultures, for which patients then have to return to the clinic for the results, and following up for INH toxicity, since in poor resource settings travelling, for example, is a significant barrier for patients. National TB care guidelines based on the ISTC with detailed guidelines for TB care for pregnant women are necessary. Improvement in TB care for pregnant women will contribute significantly to achieving the Millennium Development Goal target of halting TB by 2015 and beginning to reverse the incidence of TB [47].

\section{Additional files}

Additional file 1: NICE checklists.

Additional file 2: Comparison of ISTC and TB care practices.

\section{Abbreviations}

AFB: Acid-fast bacillus; ARDS: Acute respiratory distress syndrome; DOT: Directly observed treatment; DR: Drug resistant; HIV: Human immunodeficiency virus; IGRA: Interferon gamma release assay;

ISTC: International standards for tuberculosis care; LTBI: Latent tuberculosis infection; MDR-TB: Multidrug resistant tuberculosis; PTB: Pulmonary tuberculosis; TB: Tuberculosis; TST: Tuberculin sensitivity test; WHO: World health organization; XDR-TB: Extensively drug resistant tuberculosis.

\section{Competing interests}

The authors declare that they have no competing interests.

\section{Authors' contributions}

THN, CP and MB participated in the formulation of the methodology for this review. THN performed the literature search and reviewed all abstracts and full text articles with assistance from CP and MB. THN wrote the first draft of the manuscript and CP, PC and MB assisted in the writing and editing of the manuscript. All authors read and approved the final manuscript.

\section{Authors' information}

THN is doctoral fellow, CP is researcher, and MB is Head of the Laboratory for Mother and Child Health, Department of Public Health, IRCCS - Istituto di Ricerche Farmacologiche Mario Negri, Milan, Italy. PC is professor in the Department of Clinical Parasitology, University College London Hospitals NHS Foundation Trust, London, UK.

\section{Acknowledgements}

This work has been supported by the EC within the $7^{\text {th }}$ Framework Programme under the COHEMI project - grant agreement no. FP7-GA-261495.

\section{Author details}

${ }^{1}$ Department of Public Health, Laboratory of Maternal and Child Health, IRCCS - Istituto di Ricerche Farmacologiche Mario Negri, Via G. La Masa 19, Milan, Italy. ${ }^{2}$ Department of Clinical Parasitology, University College London Hospitals NHS Foundation Trust, London, UK. 
Received: 13 May 2014 Accepted: 6 November 2014

Published online: 19 November 2014

\section{References}

1. World health Organization: Tuberculosis and gender. [http://www.who.int/ tb/challenges/gender/en/]. Accessed 2 September 2014.

2. TB alert: TB and women. [http://www.tbalert.org/about-tb/global-tbchallenges/tb-women/]. Accessed 2 September 2014

3. World health Organization: Women and tuberculosis. [http://www.who.int/ tb/challenges/gender/women_and_tb/en/]. Accessed 2 September 2014

4. Bergeron KG, Bonebrake RG, Allen C, Gray CJ: Latent tuberculosis in pregnancy: screening and treatment. Curr Womens Health Reports 2003, 3:303-308.

5. Nhan-Chang $\mathrm{CL}$, Jones TB: Tuberculosis in pregnancy. Clin Obstet Gynecol 2010, 53:311-321.

6. World health Organization: Treatment of Tuberculosis: Guidelines for national programmes-Fourth Edition. Geneva, Switzerland: World Health Organization; 2009.

7. Turnbull ER, Kancheya NG, Harris JB, Topp SM, Henostroza G, Reid SE: A model of tuberculosis screening for pregnant women in resource-limited settings using Xpert MTB/RIF. J Pregnancy 2012, 2012:565049.

8. Albanna AS, Menzies D: Drug-resistant tuberculosis: what are the treatment options? Drugs 2011, 71:815-825.

9. Mnyani CN, Mclntyre JA: Tuberculosis in pregnancy. BJOG 2011, 118:226-231.

10. National Institute for Health and Clinical Excellence: Methods for the development of NICE public health guidance. 2006, 72-100. [http://www.nice. org.uk/guidance/ph1/resources/methods-for-development-of-nice-publichealth-guidance2]. Accessed 2 September 2014.

11. Worjoloh A, Kato-Maeda M, Osmond D, Freyre R, Aziz N, Cohan D: Interferon gamma release assay compared with the tuberculin skin test for latent tuberculosis detection in pregnancy. Obstet Gynecol 2011, 118:1363-1370.

12. Sangala WT, Briggs $P$, Theobald S, Squire SB, Kemp J: Screening for pulmonary tuberculosis: an acceptable intervention for antenatal care clients and providers? Int J Tuberc Lung Dis 2006, 10(7):789-794.

13. Gounder CR, Wada NI, Kensler C, Violari A, McIntyre J, Chaisson RE, Martinson NA: Active tuberculosis case-finding among pregnant women presenting to antenatal clinics in Soweto, South Africa. J Acquired Immune Defic Syndr 2011, 57:e77-e84.

14. Czeizel AE, Rockenbauer M, Olsen J, Sorensen HT: A population-based case-control study of the safety of oral anti-tuberculosis drug treatment during pregnancy. Int J Tuberc Lung Dis 2001, 5:564-568.

15. Tripathy SN, Tripathy SN: Tuberculosis and pregnancy. Int I Gynecol Obstet 2003, 80:247-253.

16. Jana N, Vasishta K, Saha SC, Ghosh K: Obstetrical outcomes among women with extrapulmonary tuberculosis. New Engl I Med 1999, 341:645-649.

17. Figueroa-Damian R, Redondo-Garcia JL: Pregnancy and tuberculosis: influence of treatment on perinatal outcome. Am J Perinatol 1998, 15:303-306

18. Carter EJ, Mates S: Tuberculosis during pregnancy. the Rhode Island experience, 1987 to 1991. Chest 1994, 106:1466-1470.

19. Doveren RF, Block R: Tuberculosis and pregnancy-a provincial study (1990-1996). Neth J Med 1998, 52:100-106.

20. Present PA, Comstock GW: Tuberculin sensitivity in pregnancy. Am Rev Respir Dis 1975, 112:413-416.

21. Jonnalagadda S, Payne BL, Brown E, Wamalwa D, Obimbo EM, Majiwa M, Farquhar C, Otieno P, Mbori-Ngacha D, John-Stewart G: Latent tuberculosis detection by interferon (gamma) release assay during pregnancy predicts active tuberculosis and mortality in human immunodeficiency virus type 1-infected women and their children. J Infect Dis 2010, 202:1826-1835.

22. Khan M, Pillay T, Moodley JM, Connolly CA: Maternal mortality associated with tuberculosis-HIV-1 co-infection in Durban, South Africa. AIDS 2001, 15:1857-1863.

23. Knight M, Kurinczuk JJ, Nelson-Piercy C, Spark P, Brocklehurst P: Tuberculosis in pregnancy in the UK. BJOG Int J Obstet Gynaecol 2009, 116:584-588.

24. Kothari A, Mahadevan N, Girling J: Tuberculosis and pregnancy-results of a study in a high prevalence area in London. Eur J Obstet Gynecol Reprod Biol 2006, 126:48-55.
25. Kwara A, Herold JS, Machan JT, Carter EJ: Factors associated with failure to complete isoniazid treatment for latent tuberculosis infection in Rhode Island. Chest 2008, 133:862-868.

26. Cruz CA, Caughey AB, Jasmer R: Postpartum follow-up of a positive purified protein derivative (PPD) among an indigent population. Am J Obstet Gynecol 2005, 192:1455-1457.

27. Kali PBN, Gray GE, Violari A, Chaisson RE, McIntyre JA, Martinson NA: Combining PMTCT with active case finding for tuberculosis. J Acquired Immune Defic Syndr 2006, 42:379-381.

28. Sepulveda RL, Gonzalez B, Gerszencveig R, Ferrer X, Martinez B, Sorensen $\mathrm{RU}$ : The influence of $B C G$ immunization on tuberculin reactivity in healthy Chilean women in the third trimester of pregnancy. Tuber Lung Dis 1995, 76:28-34

29. Meints $L$, Chescheir N: Screening for infectious diseases in pregnant, foreign-born women from multiple global areas. J Reprod Med Obstet Gynecol 2010, 55(10):382-386.

30. Sheriff FG, Manji KP, Manji MP, Chagani MM, Mpembeni RM, Jusabani AM, Alwani ZR, Karimjee TS: Latent tuberculosis among pregnant mothers in a resource poor setting in Northern Tanzania: a cross-sectional study. BMC Infect Dis 2010, 10:52.

31. Mofenson LM, Rodriguez EM, Hershow R, Fox HE, Landesman S, Tuomala R, Diaz C, Daniels E, Brambilla D: Mycobacterium tuberculosis infection in pregnant and nonpregnant women infected with HIV in the women and infants transmission study. Arch Intern Med 1995, 155:1066-1072.

32. Pillay T, Khan M, Moodley J, Adkihari M, Padayatchi N, Naicker V, Pillay DG, Coovadia HM: The increasing burden of tuberculosis in pregnant women, newborns and infants under 6 months of age in Durban, KwaZulu-Natal. S Afr Med J 2001, 91:983-987.

33. Margono F, Mroueh J, Garely A, White D, Duerr A, Minkoff HL: Resurgence of active tuberculosis among pregnant women. Obstet Gynecol 1994, 83:911-914

34. Lighter-Fisher J, Surette AM: Performance of an interferon-gamma release assay to diagnose latent tuberculosis infection during pregnancy. Obstet Gynecol 2012, 119(6):1088-1095.

35. Donald PR, Doherty E, Van Zyl FJ: Hearing loss in the child following streptomycin administration during pregnancy. Cent Afr J Med 1991, 37:268-271

36. Palacios E, Dallman R, Muñoz M, Hurtado R, Chalco K, Guerra D, Mestanza L, Llaro K, Bonilla C, Drobac P, Bayona J, Lygizos M, Anger H, Shin S: Drugresistant tuberculosis and pregnancy: treatment outcomes of 38 cases in Lima, Peru. Clin Infect Dis 2009, 48:1413-1419.

37. Tabarsi P, Moradi A, Baghaei P, Marjani M, Shamaei M, Mansouri N, Chitsaz E, Farnia P, Mansouri D, Masjedi M, Velayati A: Standardised second-line treatment of multidrug-resistant tuberculosis during pregnancy. Int $J$ Tuberc Lung Dis 2011, 15:547-550.

38. Cheng VC1, Woo PC, Lau SK, Cheung CH, Yung RW, Yam LY, Yuen KY: Peripartum tuberculosis as a form of immunorestitution disease. Eur $J$ Clin Microbiol Infect Dis 2003, 22:313-317.

39. Franks AL, Binkin NJ, Snider J, Rokaw WM, Becker S: Isoniazid hepatitis among pregnant and postpartum Hispanic patients. Public Health Rep 1989, 104:151-155.

40. Sackoff JE, Pfeiffer MR, Driver CR, Streett LS, Munsiff SS, DeHovitz JA: Tuberculosis prevention for non-US-born pregnant women. Am J Obstet Gynecol 2006, 194:451-456.

41. Gupta A, Chandrasekhar A, Gupte N, Patil S, Bhosale R, Sambarey P, Ghorpade S, Nayak U, Garda L, Sastry J, Bharadwaj R, Bollinger RC, Byramjee Jeejeebhoy Medical College-Johns Hopkins University Study Group: Symptom screening among HIV-infected pregnant women is acceptable and has high negative predictive value for active tuberculosis. Clin Infect Dis 2011, 53:1015-1018.

42. Keskin N, Yilmaz S: Pregnancy and tuberculosis: to assess tuberculosis cases in pregnancy in a developing region retrospectively and two case reports. Arch Gynecol Obstet 2008, 278(5):451-454.

43. De Oliveira HB, Mateus SHR: Characterization of multidrug-resistant tuberculosis during pregnancy in campinas, State of Sao Paulo, Brazil, from 1995 to 2007. Rev Soc Bras Med Trop 2011, 44:627-630.

44. Khan M, Pillay T, Moodley J, Ramjee A, Padayatchi N: Pregnancies complicated by multidrug-resistant tuberculosis and HIV co-infection in Durban, South Africa. Int J Tuberc Lung Dis 2007, 11:706-708.

45. Llewelyn M, Cropley I, Wilkinson RJ, Davidson RN: Tuberculosis diagnosed during pregnancy: a prospective study from London. Thorax 2000 55:129-132. 
46. Tuberculosis Coalition for Technical Assistance: International Standards for Tuberculosis Care (ISTC). The Hague: Tuberculosis Coalition for Technical Assistance; 2006. [http://www.who.int/tb/publications/2006/istc_report.pdf]. Accessed 2 September 2014

47. Nations U: United Nations Millennium Development Goals Report 2012. New York, NY: United Nations; 2012. [http://www.un.org/millenniumgoals/reports. shtml]. Accessed 2 September 2014

doi:10.1186/s12879-014-0617-x

Cite this article as: Nguyen et al:: Tuberculosis care for pregnant women: a systematic review. BMC Infectious Diseases 2014 14x:617.

Submit your next manuscript to BioMed Central and take full advantage of:

- Convenient online submission

- Thorough peer review

- No space constraints or color figure charges

- Immediate publication on acceptance

- Inclusion in PubMed, CAS, Scopus and Google Scholar

- Research which is freely available for redistribution

Submit your manuscript at www.biomedcentral.com/submit
( Biomed Central 